\title{
Teoría política y republicanismo. Imaginario e historicidad. Un debate necesario
}

\author{
Manuel Castillo Ochoa \\ Universidad Ricardo Palma \\ manuel.castillo@urp.edu.pe
}

\begin{abstract}
RESUMEN
Con la proximidad de que el Perú cumpla en el 2021 doscientos años como bicentenario se ha suscitado un debate que cruza no solo los predios de la historiografía nacional sino incluso los de las ciencias sociales en su conjunto. Ese «renacimiento» de la propuesta estatal republicana aunque no es nueva en el Perú, sí puede serlo de la forma en que ahora se la encara y de las consecuencias que ella envuelve para las interpretaciones de la configuración de la realidad nacional. El presente artículo indaga sobre ese renacer teórico político republicano, analiza los alcances de una de sus principales divulgadoras y busca presentar un balance teórico de las mismas desde la tradición del pensamiento crítico nacional.
\end{abstract}

Palabras clave: Ciudadanía, República, gobierno, democracia, ciclo político

\section{Political theory and Republicanism Imaginary and historicity - A necessary debate}

\begin{abstract}
Soon, in the year 2021, Peru will reach its bicentennial as a Nation. That is why a debate has arisen and crosses not only the domains of national historiography but even those of the social sciences as a whole. That «revival» of the republican state proposal, it is not new in Peru, but may be so, now that it is confronted and on the other hand, in relation to the consequences that these actions will involve to give way interpretations of the configuration of the Peruvian reality. The present article inquiries about that theoretical, political and republican rebirth, analysing the scope of one of its main disseminators. Thus, it seeks to present a theoretical balance, of the same, from the tradition of national critical thinking.
\end{abstract}

KeYwords: Citizenship, Republic, government, democracy, political cycle. 
Si se revisa la historiografía nacional puede observarse que cada cierto tiempo surgen polémicas interpretativas sobre los diversos sucesos que han acaecido en la historia nacional o, para decirlo con mayor claridad, sobre las diversas interpretaciones qué enlazando hechos y acontecimientos de la vida histórica nacional, nos presentaban diferentes narrativas interpretativas sobre las mismas. Y si usamos el adjetivo de "narrativas interpretativas" no es solo por un prurito de vanguardismo conceptual, aun cuando pueda haber ocurrido que su uso ha adquirido carta de ciudadanía en los diversos medios expresivos nacionales — periodismo gráfico, televisivo, radio, opinología columnística, etc.- sino que, probablemente después de la difusión que adquirió la escuela post estructuralista foucaltiana y derrideana y lo que actualmente se denomina la "perspectiva interpretativa», o siguiendo a Zizeck «la mirada paralaje», sabemos que lo interpretativo no es nada trivial sino que constituye la esencia misma del quehacer cultural explicativo. La esencia humana o, siguiendo las enseńanzas de la filología niesztchiana e incluso la de Habermas (1987), la de la especie humana consiste, precisamente, interpretar irremisiblemente lo contextual fáctico que lo rodea y mapearlo calificativamente en macro conceptualizaciones ordenadoras de sentido1.

Pero como sabemos, también, estas macro ordenaciones conceptuales adquieren condición de legitimidad enraizándose sobre la temporalidad historicista en la que cada sociedad ubica a sus miembros pertenecientes a la misma. Pero como la temporalidad historicista no sería más que sustancia vacía sino fuera por la acción productora de actores sociales que, a la vez que piensan - y por eso mismo- su historicidad reflexivamente, van insertando configuraciones de sentido en el imaginario colectivo de cada sociedad, grupo, comunidad, federación, nacionalidad o nación, hasta producir los imaginarios de sentido que la historia y la historiografía busca indagar e interpretar. Y es en esa producción de los actores productores de sentido en lo que hay que topografíar e investigar para observar por qué precisamente, maquinaron esas ideas y no otras. Por qué nos entregan cada cierto tiempo un nuevo arsenal interpretativo, nuevos mapas conceptuales que buscan suplantar a los antiguos, nuevas narrativas, nuevos discursos. Obviamente los cambios sucesivos en la estructura material de la historicidad pueden ser observados como causas primarias, pero ellas se agotan en si mismas en cuanto fundamento explicativos sino se tiene en cuenta el quehacer de la traducción que de esas condiciones realizan los actores agentes portadores de esa historicidad. Entonces se hace imperativo realizar una arqueología del saber y del conocer, pero también del cómo se coloca y se entrega a la sociedad esos nuevos dispositivos de sentido para que, con el transcurso de su uso y su difusión — si es que algunas de ellas adquieren legitimidad y no queden como descartables producciones de grupitos que quedaron en la inmemoria

\footnotetext{
$1 \quad$ Si se trata de «interpretaciones» la obra clásica de Foucault, aún con el paso del tiempo sigue siendo indispensable. Véase su clásico Las palabras y las cosas, y tómese en cuenta la metáfora que emplea sobre Velásquez que como pintor de las Meninas ordena su universo - el episteme — en incluye a sus personajes en diversos roles posicionales.
} 
histórica o de «no historia»— y con el transcurrir del tiempo pueda decirse de ellas que no solo se insertaron en sus respectivas historias interpretativas sociales sino que reconfiguraron el mapa de sentido de las mismas.

Por eso cada que fallece un renombrado autor que para su generación y contemporaneidad adquirió notoriedad y relevancia, queda, para los que lo continúan, esa incertidumbre cósmica de comparar la actualidad temporal mínima y microscópica con la inmensidad del tiempo histórico de larga duración, para ver si las producciones de sentido del pensamiento, en este caso individual, de determinado autor, tendrán la «transcendentalidad histórica» de lo que puede perdurar y superar la corta duración de décadas y siglos. Y, también por lo mismo, si observamos los debates interpretativos que se están haciendo en la historiografía nacional y en las ciencias sociales en su conjunto sobre lo acaecido entre nosotros o en las «interpretaciones de nuestra historia», podemos contemplar que bajo el ánimo de los tiempos efímeros y cambiantes que nos toca vivir todo se reinterpreta rápidamente, todo se trastoca sin interrupción y detenimiento. Una pulsión de cambio arrolladora que no solo se da en la tecnologización conmutativa de enlaces globalizadores trasnacionales sino que empuja a la estética y sus diversas variantes de oficio, a los gustos y costumbres de cada sociedad, y, obviamente, a los contenidos de los imaginarios historiográficos.

Una breve y apretada revisión — solo de algunos casos ejemplares— de los cambios interpretativos que se dan en esa lógica entre nosotros, viéndolo desde nuestra antigua historia y posteriormente para focalizarnos en el viviente siglo XXI, el cual es el interés de este artículo, desde sus comienzos a la actualidad, nos muestra lo siguiente. Si nos remitimos a la historiografía andina prehispánica las tradicionales conceptualizaciones que dieron sentido a esa sociedad son traspasadas y suplantadas por otras. Veamos lo más elemental. ¿Fueron una sociedad pacífica? Ahora sabemos que no. Investigaciones arqueológicas dan consistencia para pronunciarse sobre innumerables ritos de sacrificios humanos. Niños, mujeres, hombres eran víctimas de sacrificios en masa, en aras de ofrendas mágico-sacralicias a sus deidades. Si bien habían superado el canibalismo de los aztecas y en esa perspectiva superaban a los grupos tribales primarios que por continuar con el ciclo alimentario de la caza y recolección no habían ingresado al ciclo de la domesticación pecuaria y la agricultura como sí lo hicieron desde Caral hasta el Tiahuanaco y, por consiguiente, no practicaban el canibalismo, si sacrificaban personas por otros motivos. Desde Chavín de Huantar hasta el Imperio del Tiahuanaco se ha podido rastrear ese apego mágico al sacrificio humano. Entonces, si para Garcilaso de la Vega, en su segundo tomo de los Comentarios Reales, los Incas fueron pacíficos, redistribuidores de la riqueza, justos y correctos gobernantes, tal como durante mucho tiempo 
se enseñó en los libros de colegio, ahora sabemos que tal interpretación ha quedado desmistificada ${ }^{2}$.

¿Fueron trece los incas? María Roswtorowski (1983) dejó entreabierta, apoyada en los estudios de Murra (1975) y Watchel, una puerta que ella, probablemente por cuidados académicos, no avanzó más. Si las concepciones Incas se basaban en el Hurin y el Hanan, para decirlo de la manera más simplista, después de todo una forma cognitiva epistémica propia de las sociedades de contemplación y semejanza de la naturaleza y base conceptual de las sociedades tradicionales primarias, por consiguiente no tenían porqué parecerse las europeas. Por ejemplo, una concepción de estructura dual, que se reflejó en estructuras de Poder, y en sus formas de administración comunales, se alejaba radicalmente de una concepción centralista unitaria como la europea. En el mundo andino un doble poder asentaba las condiciones de su legitimidad y, en esa lógica, era dual, un sentido de unidad y confrontación guerrera en su seno. Hermanos pero enemigos, colectivos pero disociados, en lucha insolidarias pero unidos de forma comunal. Era obvio que el anacronismo inquisitorial hispánico no podía comprender esa forma de poder andino. Observadores de un poder de vértice, unitario, de principados que para realizar el paso de señores feudales a príncipes y posteriormente a monarcas, había tenido que cohesionar el orden bajo mandos únicos y en luchas bajo mantos imaginarios religiosos de suma cero, cómo entender el poder dual. En su anacronismo buscaron un rey, un solo príncipe, y lo encontraron. El imaginario ve lo que quiere ver, por eso es justamente un imaginario. ¿Doce trece o catorce Incas? ¿El mismo número de los acompañantes de Jesús en la última cena? Nuevamente una revisión interpretativa de la historia, esta vez andina, que se echa abajo «interpretaciones» anteriores. Hubieron muchos más incas de lo que nos han enseñado en la difusión pedagógica nacional.

La Colonia y el Virreinato han sido también émulos de nuevas interpretaciones sobre las tradicionales anteriores. Pero en este caso la historiografía nacional sí ha hecho su work in progress. Se ha construido y se ha deconstruido varias veces ese período histórico que casi deja sin novedad de análisis para nuevas reinterpretaciones. Probablemente en el centro de esos debates se encuentre la figura de Francisco Pizarro. Si la generación del treinta lo vio, en los trabajos de ese colectivo tan brillante en la historia nacional, como colonizador y genocida, y en su biografía personal como analfabeto y de familia menesterosa cuidadora de chanchos en su España seminal, en los años cincuenta y sesenta se trató de redimir su figura y presentarlo con alcurnia y tradición ya que su familia era propietaria de haciendas de porcinos y no solo cuidadores de la misma. Pero su revalorización más compleja es aquella que presenta a Pizarro no como colonizador sino como liberador, aquel que nos trajo la cristiandad, la salida del pecado terrenal y

2 En la literatura reciente de textos de historia nacional existe una producción de textos que desmistifican sucesos comúnmente aceptados en el sentido común. Véase, como ejemplo, de Alfonso Klauer Los abismos del Cóndor, Ediciones del autor, Lima, 2000. 
nuestra llegada al cielo, la palabra de Dios sobre el paganismo salvaje tradicional andino, el rechazo de la plurisexualidad andina por la hipócrita heterosexualidad española doctrinaria, la escritura y la imprenta. Cómo llamarlo, entonces, genocida conquistador a aquel que nos libera de las improntas de la naturaleza y te hace llegar a la universalidad de lo sagrado. Esta revalorización viene, obviamente, tomada de la mano de un pensamiento ultraconservador, nueva sensibilidad de época que trae el inicial siglo XxI globalizador al mundo occidental, pero no solo occidental europeo sino también entre nosotros —el occidente bizarro - como veremos posteriormente.

Recientemente se ha reinterpretado, como ejemplo, la figura de las «tapadas» en el espacio colonial urbano. Dibujada como figura femenina excelsa, y halagada en muchos trabajos de la historiografía tradicional, ahora se conoce que debajo de la manta y la mirada de un sólo ojo, se escondían cuerpos masculinos. De tal modo que el matrimonio heterosexual y monogámico visibilizado como práctica religiosa virreinal no lo era tanto y convivía con costumbres sexuales de otra índole. Demostración de que las narrativas reinterpretativas van cambiando empujadas por el descubrimiento de nuevas insersiones en el imaginario nacional ${ }^{3}$.

El caso de la República es, quizás, uno de los ejemplos más remarcables que cómo se han y se van insertando y reinsertando cambios en los imaginarios tradicionales. Tal es el caso de que se podría hablar de ciclos de reinterpretación. Si la generación del novecientos puso sobre el diagnóstico historiográfico la idea de la élite conductora y el mendigo sentado en un banco de oro para graficar la riqueza peruana y consolidar la expectativa de crecimiento extractivo liberal para el Perú, con ello inicio un ciclo de interpretaciones que pronto sería impugnado. La generación del treinta acabaría y buscaría cancelar esa narrativa desmontando la idea de la élite conductora como insolidaria y ajena al verdadero actor nacional, lo indio y, por consiguiente, alterar la noción de «proyecto nacional civilista» en base a las exportaciones colocando los intereses de clase y el inicio de una industrialización mercado internista de integración clasista. De lo indio a formación de ciudadanías, y de ciudadanías a la integración republicana. Obviamente un nuevo pacto contractual Estado-sociedad que supere el incumplimiento.

Pero estas reinterpretaciones no solo atañen a la vida republicana del siglo veinte, sino incluso a sus inicios emancipadores. ¿Fue una revolución emancipadora empujada por fuerzas interiores que se apoyaron en la ayuda externa o fue el impulso de los ejércitos libertarios externos — tanto de San Martín como de Bolívar- los que detonaron nuestra emancipación ante la vida muelle de criollos enlazados sojuzgadamente a la vida virreinal? Ahora todo es revisado y revisitado, y las interpretaciones, mientras no exista una narrativa hegemónica qué construyendo un horizonte de sentido, desplace

3 Véase el Mercurio Peruano No.94 de 1793 «Carta sobre los Maricones». Ediciones El Mercurio Peruano, Tomo III, Lima, 1793. 
y minimice a las otras, nos hará sentir como en un tiempo de indeterminabilidades e incertidumbres. Pero cuál es la base, la latencia que empuja a una cultura de la sospecha de las interpretaciones, de casi todas las interpretaciones y que se expresa en un sinnúmero de afirmaciones que a muchos analistas hacen decir que a más información más desinformación. ¿Será que ese es el espíritu de los tiempos globalizadores, será que la proliferación de muchas voces interpretativas acobijadas en medios enunciadores de diversidad multimedia variada, nos ha llevado a esa situación? Aunque esa idea pudiera ser parte de la realidad intempestiva de la sensación de "perdida de la razón", apelemos aquí a una respuesta más macrosocial. El punto de equilibrio de los diversos actores sociales pareciera situarse en medio de un empate epistemológico por el cual ninguno de ellos obtiene, en el conflicto interpretativo, la fuerza suficiente para establecer su narrativa como la central hegemónica.

Pero una vez señalado la afirmación anterior estamos tocando uno de los focos nodales de la reproducción social. El de que toda sociedad necesita indefectiblemente un marco de referencia, un framework por medio del cual ordenarse y ordenar su situación social, ordenar al fin de cuentas su existencia. El desorden que produce el conflicto de las narrativas, la lucha de las interpretaciones no es la causalidad del desorden, es un síntoma de una causa que, justamente, se nos invisibiliza en el bosque exuberante de narrativas en conflicto. Pero tampoco se trata de producir más reinterpretaciones pues las mismas son prontamente descartadas o, hablando metafóricamente, ellas permanecen en un vació es espera de que algún actor las recoja. Pero antes de avanzar más, demos respuesta a una pregunta que nos sale al frente. Aun cuando proliferan muchas interpretaciones porqué algunas son dejadas de lado rápidamente y otras prevalecen. Una respuesta es que no todas presentan la misma asimetría de anomalías. Es decir, hay una desigualdad en la presentación de la calidad de las interpretaciones, pero eso no basta. También la narrativa que está en juego con muchas otras, además de preservar la calidad de su propuesta, o sea, de sus no-anomalías, debe recoger la fenomenología integral del actor para el cual ha sido enunciado.

Pongamos un ejemplo más sencillo para desglosar lo señalado. Cuando Hernando de Soto (1986) nómino con empresarios informales, al final de cuentas de nuevo tipo, como nuevos actores emergentes de "negocios» después del desplazamiento de la migración de los años cuarenta y cincuenta, a los informales y los integra, en la semántica del discurso de la palabra, como empresarios, no sólo los señala a través de lo que han producido en su economía, sino que los interpela y les da una nueva identidad. Ni marginales, como seńalaba la Cepal, ni lumpen proletariado como señalaba en ese entonces la izquierda, ni delincuentes invasores como los tipificaba el criollismo legalista limeño. Es ese nombramiento había entonces un doble juego al interior de la interpelación; el de la identidad y el de la economía. Pero si bien ambas dimensiones las podemos separar en un plano conceptual, en realidad obedecen a una sola dimensión en el plano de lo 
social. Ahí está entonces el por qué una de las interpretaciones gane a las otras, desplace a las otras, hegemonice a las otras.

Regresemos ahora a una de las últimas reinterpretaciones que se ha introducido en la historiografía nacional: el consabido tema de la República.

A finales del siglo veinte e inicios del siglo veintiuno, del cual venimos terminando ya una segunda década, se produjeron un conjunto de acontecimientos políticos que marcaron fuertemente la vida social peruana. La crisis del fujimorismo, el escándalo de la corrupción, de la des-institucionalización, del control de un poder sobre otros poderes del Estado, y en especial, y en los que nos interesa, las reinterpretaciones que desde la hermenéutica del derecho se aprovechaban para trastocamientos anti constitucionales, etc. puso sobre el debate el tema de la gobernabilidad. La temática de la gobernabilidad, por otro lado, había tenido su carta de inauguración en las transiciones desde gobiernos autoritarios hacia procesos de democratización en los gobiernos del cono sur, herencia política autoritaria de las décadas del sesenta, setenta y ochenta latinoamericanos. Lo que colocaba sobre el tapete la gobernabilidad, visto en modo teórico, era recoger la vieja tradición politicológica estadounidense fraseaba como institucionalidad democrática, para decirlo en términos amplios. Es decir, se esparcía la idea de que así como hay indicadores del desarrollo económicos mediante el cual se pueden establecer patrones de comparación entre diferentes países, así mismo había el desarrollo político y con sus respectivos indicadores se pueden establecer, también, patrones de comparación entre diversos países. Ello condujo a una alianza conceptual entre dos grandes matrices de análisis políticos: El afianzamiento de la necesidad del pacto contractualista y la necesidad, asimismo, del institucionalismo. Se unían así dos grandes herencias teóricas del pensamiento político occidental, la escuela del contractualismo mayormente proveniente de Europa occidental y la escuela del neo-institucionalismo que había sido prevalente en la politología estadounidense. No esta demás decir que se incluían también otras temáticas que arraigaban sobre lo mismo y que no las incluimos aquí por ánimo de simplificación expositiva. Sin embargo, tengamos en cuenta a una de ellas por su singular importancia. La jurisprudencia y su importancia en los manejos institucionales. A fin de cuenta la reforma del derecho. Pero la base objetiva de fondo era propiciar un reencuentro entre una ciudadanía efectiva en sus derechos, pero también en sus deberes y el Estado, el ente normativo jurídico de la sociedad también con sus derechos y deberes. Es de suponer que el funcionamiento de ambos acertada y eficientemente dará paso al desarrollo político. El modelo a seguir eran los países anglos y los países nórdicos de Europa. El trasfondo, la democracia.

Obviamente, y bajo estos supuestos, la temática de la gobernalibilidad y su derivación en el accionar en la gestión pública, la gobernanza, hizo prontamente streaming en América Latina. Se convirtió en una ola de institucionalidad democrática que se enlazaba a otras de inicio del siglo xxi: globalización, fin de la historia, reducción de la 
desigualdad, fortalecimiento de derechos humanos, medio ambiente, ecología, género. Pero en ningún caso se dejaba de lado el trasfondo: fortalecimiento ciudadano.

Prontamente en el Perú, unido a la crisis de los paradigmas, al auge de las narrativas, de las reinterpretaciones, de la información trasnacional, de la globalización, la temática de la ciudadanización se encontraba en el centro del interés. La historiografía nacional no había sido ajena a estos menesteres y hasta se editaron libros ya no sólo de nuevas propuestas reinterpretativas sino de historia contrafáctica, es decir, de cómo pudo ser la historia que no fue. No había más que dar un mínimo salto para ingresar al tema de la República y porque no se había configurado en nosotros tal y como debió ser. El tan mentado tema de la «Promesa de la vida republicana» que señalara a inicios de los ochentas Basadre y ya en las postrimerías de su vida, relució y fue rememorado más que nunca. Pero como, y pese a los esfuerzos del gobierno iniciador nuestro del siglo XXI, Paniagua, la república no cuajaba ni cristalizaba la promesa democratizadora modernista, prontamente hicieron su aparición dos líneas de interpretación frente ese déficit.

Por un lado, desde la politología, adhiriéndose a la aparición y proliferación de escuelas de politología y de «analistas políticos» en los medios, se tomo el tema como república sin ciudadanos o ciudadanos sin república. Vergara (2013) tuvo la iniciativa de editar un libro bajo ese título que prontamente adquirió reconocimiento y que hasta el momento lleva varias ediciones realizadas. Por otro lado, desde la historia, Carmen Mc Evoy (1997) editó el libro La utopía republicana: Ideales y realidades en la formación de la cultura politica peruana (1871-1919)4 y también rápidamente adquirió carta de ciudadanía, se difundió nacionalmente y su autora paso de ser un personaje desconocido décadas anteriores a adquirir notoriedad mediática y a escribir columnas semanales en uno de los diarios de mayor circulación nacional. Posteriormente ha escrito otros libros con temática similar, digamos que es su tema insignia, emblemático.

Es de relativa y fácil comprensión que el retomar de la vida democrática después de la caída del gobierno de Fujimori, y el afianzamiento del sistema democrático en los que va de las dos décadas trascurridas del siglo actual, la ciudadanía, la democracia, el pacto estado-sociedad, la política en general, este a la orden de las noticias del día a día. Y ahí radica la fortaleza y oportunidad de reinterpretar nuevamente nuestra historia republicana a fin de observar las falencias de nuestro tramitar histórico para que tal promesa de una república moderna y occidentalizada no se haya cumplido y siga constituyéndose en una promesa en espera de su realización. Más aún si ella retoma la perspectiva de hacerlo desde el ángulo cultural, uno de los aspectos que más ha sobresalido en los análisis sociales y políticos desde que la globalización lograra presencia hegemónica. Pero esa

4 Si bien es cierto que ya en 1994 la autora había publicado un texto sobre el gobierno de Manuel Pardo, y es en 1997 cuando pública la obra en referencia, se puede señalar que ella se inscribe en el clima de democratización suscitada a fines del siglo xx e inicios del siglo xxi, y bajo una opción estratégico editorial, su obra se ha relevado al acercarnos al bi-centenario de la república del Perú. 
temática de la vida republicana, aunque fuera fraseada en los años treinta por Basadre al señalar que prácticamente no había estado en el Perú sino bajo forma coloidal (1931), el famoso estilo político «sultanista» en sus propias palabras, ha pasado por varios episodios que es necesario de tenerlos en cuenta al analizar su recorrido.

Basadre ciertamente le dio carta de ciudadanía a tal temática entre nosotros. Su clásico y temprano libro Perú, problema y posibilidad escrito en 1931, así lo demuestra. Su conferencia en 1980, ante la Cade de ese ańo, en el que habló de la promesa incumplida y señala los «tipos de personalidad» peruana que por sus propias características idiosincráticas han malogrado esa posibilidad de cumplimiento, dan constancia de ello. Sin embargo, tal temática prácticamente quedó de lado por las respectivas posiciones políticas posteriores. La izquierda en su conjunto y en los años que más presencia tuvo, en ese ciclo que va desde fines de los sesentas, setentas hasta mediados de los ochentas, hasta prácticamente invisibilizarse a fines de siglo veinte, no hablaba mayormente de república, ni sus intelectuales hacían mayormente análisis sobre esa temática. Era, se puede decir, un tema prescindible para ella. El tema ha entrado ciertamente por el lado de los intelectuales de derecha y por el lado del derecho, de la ley y su funcionamiento. Una izquierda setentera bajo un ánimo antisistémico como fue el horizonte marxista de esos años, dejaba de lado el funcionamiento propio y los mecanismos de reproducción del orden social como son las leyes, después de todo ellas - las leyes, el funcionamiento del derecho, y la jurisprudencia - son como tuercas y tornillos de la sociedad en una perspectiva republicana o sea pro sistémica.

En ese sentido la idea de república y básicamente la idea de su bien o mal, pésimo o regular funcionamiento interesa a los que están dentro del sistema, es decir empoderados e imbuidos dentro de ella. Esa idea poco representa, más allá de su uso utilitario en tanto "me toca vivir con ella», para segmentos sociales que pretendían cambiar la vida republicana desde su raíz. Y es ahí donde radica el interés que ha suscitado el tema que trata Mc Evoy (1994, 1997), la historia de nuestros desafueros republicanos.

En el libro señalado, Mc Evoy afirma que no ha habido un interés por revisar la subjetividad de la vida republicana ni un interés por lo republicano en tanto construcción de un Estado que integre responsablemente a la mayoría de sus ciudadanos, que sea, así mismo, responsable de su función pública, modernizado, etc. En tanto los «usos y hábitos» de los académicos que analizaron el período político que va desde 1871 hasta 1919, ciclo político que ella estudia, por las concepciones de marcos referenciales teóricos -teoría de la dependencia, estructuralismo, mirada ideologizada hacia la sociedad de ese tiempo- los aislaba bajo ese tipo de enfoque para investigar la cultura política y la subjetividad que la misma implica, en ese período histórico. Después de todo el juego de la política es, simplificando, cultura y eso era, precisamente, lo que se dejaba de lado. Criticando a autores renombrados — desde extranjeros como Gunder Frank, considerado uno de los padres fundadores de la teoría de dependencia, hasta nacionales como 
Heraclio Bonilla (1972), Julio Cotler (1978), Ernesto Yépez (1972) por asimilarse a una sucinta generalización sobre ese período, que se puede frasear en la idea de que no había Estado ni intentos por organizar una nación moderna de integración ciudadana, dejan de lado y desdeńan uno de los intentos más interesantes que hubo en ese período como fue el gobierno de Manuel Pardo fundador del partido civilista y presidente del Perú entre 1872 y 1876.

Según la autora el autocratismo dictatorial del gobierno de Ramón Castilla y, posteriormente al período de Manuel Pardo, la recomposición oligárquica anti democratizadora y elitistamente excluyente que culminó en el gobierno de Nicolás de Piérola, impidió ver la importancia para la construcción de un proyecto republicano estatal moderno en el gobierno del mencionado Pardo. Situado como en un entre paréntesis histórico el gobierno de Manuel Pardo fue un momento inigualable de construcción republicana. La emergencia de un gobierno qué apelando a la educación y formación de una cultura cívica, a la formación de lo que en ese momento se denominó históricamente el «Estado Ciudadano», algo así como un antecedente temprano del gobierno de la "Patria Nueva» que inaugurará en la década de 1920 el gobierno de Leguía, trato de innovar y recrear y desplazar la subjetividad política caudillista, que se había convertido en una costumbre, en una cultura política anti-moderna y anticiudadana, por un cultura política cívica, basada en derechos ciudadanos.

¿Por qué los analistas de textos dedicados a ese período de nuestra vida republicana no vieron ni percibieron la importancia del «momento Manuel Pardo», por qué se mostraron «ciegos» ante la importancia histórica? ¿Por qué también los autores del segundo tomo del «Pensamiento Político Peruano» que editara Adrianzén en 1987 pasan por alto ese ciclo de vital importancia para entender la frustración democrática de nuestra historia? Mc Evoy culpabiliza a la mirada y perspectiva estructuralista encarnada en la teoría de la dependencia. Autores como Bonilla, Cotler, Yépez, incluso Flores Galindo y Burga (1980), sesgaron su análisis al adscribirse a un sentido común que, generalizando nuestros acontecimientos históricos, leían la historia republicana de nuestro siglo XIX ideológicamente. No había Estado ni se podía formalizarlo políticamente porque predominaba la fragmentación, la segmentarización, la economía archipiélago, y desde este sesgo arraigadamente economicista —estructural— no podía emerger una fuerza que integrara a la nación y formara un estado bajo civismo republicano. El Estado criollo que existía desde la independencia era un Estado coloidal, informe, gelatinoso que no aglutinaba, sino que se deshilachaba en clientelas, grandes corrupciones, caudillos militaristas heredados de las gestas coloniales o de la fallida confederación Perú-boliviana, presidentes que solamente duraban meses y días. La falla de origen, en primer lugar, era la afirmada por Cotler como la "herencia colonial» de parte de los criollos nativos post independentistas y, en segundo lugar, en la continuidad colonialista graficada en el desplazamiento de los españoles por los ingleses. 
Ante ello, Mc Evoy busca la reinterpretación de la historia, la colocación de otra narrativa, desde otro espacio de enunciación. Ya no desde la orilla de la estructura económica, de la dependencia, del economicismo sino de la subjetivación, de los discursos, de las narrativas de los actores encarnados por los propios protagonistas de ese momento. Para ella la simplificación dependentista no permite ver la riqueza de la propia historia y para ello recurre a los nuevos hermeneutas de la subjetividad y el discurso: Habermas (1987), Gadamer (2010), autores europeos citada por ella misma en su introducción. Pasa de las explicaciones generalistas dependentistas al detallismo discursivo de la propia palabra escrita de los actores, registrada en innumerables archivos, cartas, escritos notarias. Ahí trata de descubrir la subjetividad del momento histórico, la sensibilidad política de ese momento, y descubre, en primer lugar, porque el desdén de nuestros historiadores anteriores a su propia historia y, en segundo lugar, qué sí existió cultura cívica, que sí existieron actores políticos de visión nacional que buscaban pasar desde la particularidad de nuestro localismo andino y criollo costeño, a la universalidad abstracta de la construcción de un estado nacional. Que si hubieron reflexiones sistemáticas pensadas e intentos modernistas de construcción estatal, proyectos de integración ciudadano, de fortalecimiento de derechos. Y buscó cristalizarse en el momento del gobierno de Manuel Pardo.

\section{Pero, ¿̨ue así?}

Sería largo y tedioso introducirnos en este breve ensayo en los pormenores y detalles de la vida política republicana en los años que van previos a la guerra del Pacífico hasta la segunda década del siglo xx, innumerables autores ya lo han efectuado, pero valgan unas cuantas frases con relación al tema de nuestro interés.

Al final de lo que se trata es de introducir insertar una nueva reinterpretación en la historia política nacional. No significa ello que no haya habido trabajos que tocaran esa temática anteriormente. Varios trabajos de diversos autores muestran que el tema sí fue tratado, pero ciertamente la idea que ganó hegemonía fue la de que en la historia de la vida política del siglo XIX no hubo una cultura cívica política, ni un horizonte ideas sobre la configuración de un estado democrático republicano. La idea que mayormente ganó cuerpo como sentido común y llegó hasta los libros de divulgación histórica mas sencillos fue que en el siglo xix el caudillismo extremo, el personalismo autoritario hacendatario, el patriarcalismo y sus secuelas discriminatorias y racistas de masculinismo exacerbado, dejaron tal marca en la cultura política de ese período que las ideas cívicas republicanas y democráticas casi no tenían opción. Autores como Basadre así lo dieron a entender a lo largo de su inmensa obra histórica. No solo ello. Basadre (1983) mismo fue de alguna forma acusado de hacer una historia política centrada en los avatares de 
los actores políticos y de desdeñar la opción de los actores masivos; indios, ciudadanos empobrecidos, serviles y esclavos hasta la segunda mitad de ese siglo. Para resumirlo en calificativos sociológicos a la mano, el sistema de dominación oligárquico señorial y su secuela de caudillismo restringido y excluyente no permitieron la emergencia ni mucho menos, la difuminación de ideas democráticas. Así mismo lo reafirmaron también los intelectuales más destacados de la generación del veinte. Tanto Haya de la Torre (1936, 2010) como José Carlos Mariátegui $(1928,1987)$ también se mostraron de acuerdo en esas afirmaciones. Aún más, la pretendida revolución anti oligárquica que buscó realizar el APRA conducido por Haya de la Torre era justamente, mediante la acción del partido que él dirigía, tratar de cambiar y cancelar esa forma de dominación oligárquica hacendataria caudillista y modernizar la vida política. Por eso fundo el partido que él dirigió.

Por otro lado, en Mariátegui, que también se adhería a esa visión —antigamonalista, antisemifeudal—y que daba cuenta del «estilo» cultural de la dominación hacendataria nacional, en su camino como intelectual fue desdeñar a los actores que hacían política, para él menuda, de cerrados círculos, capitalina, y minúscula y descubrir al verdadero y mayoritario actor que podría llevar un cambio de envergadura sobre los restringidos círculos políticos criollos: el indio, acompañado por el proletariado. De ahí sus acercamientos a los indigenistas y sus ensayos sobre el problema del indio.

Significó esto: ¿Qué esos analistas no vieron los meandros de la política criolla, el detallismo de la cultura política de los actores políticos criollos de ese momento, sus conflictos y luchas interiores, sus escarceos congresales, sus discursos y panegíricos? ¿Se le puede achacar a Basadre no haber estudiado con intensidad la vida política del siglo XIX republicano conociendo la obra que él produjo? ¿No será que a tanto de dejarse llevar por la ola de las reinterpretaciones y bajo el ansía de colocar nuevas narrativas estamos echando el agua sucia de la bañera junto con el niño?

$\mathrm{Y}$ es aquí donde debemos recoger lo que seńalábamos anteriormente. Los actores no son solo campo de subjetividad, sino a la vez que son eso, son también subjetividad anclada sobre su propio sistema de historicidad. Confundir esas dos dimensiones, aunque sean construcciones tóricas para comprender la realidad, aunque en la misma no aparezcan por separado, puede llevar a penosas interpretaciones que nos alejan, y confunden la historiografía, antes que esclarecerla y proveer aportes efectivos.

Y justamente lo que hicieron tanto Haya de la Torre como Mariátegui, como también Basadre y otros autores posteriores a ellos es no confundir la construcción del Estado -que de eso se trata en todo momento y por eso se denomina Utopía Republicana- y la forma en que los propios actores de la historicidad de ese momento pensaron y verbalizaron a través del mundo simbólico del imaginario en el cual ellos se situaban, las condiciones de sus luchas y sus conflictos, de sus múltiples enfrentamientos y devaneos (Pardo acabó, tal como se conoce, cobijado por Balta para que no lo mataran y su lucha 
contra el armamentismo de los caudillos, produjo, irónicamente la fortaleza armamentista chilena).

Si se analiza solo una de esas dos dimensiones, por ejemplo, la cultura política y la subjetividad cívica de la época, podemos caer en sublimar lo que los actores decían y escribían en sus discurso y textos, en la voluntad política que ellos se habían trazado como tarea, pero bien sabemos ahora que lo que los actores piensan de si mismo es la mayor parte de las veces reflejos falseados de su propia historia, es decir, ideología como forma falseada de la realidad en que vivían. Nadie llega a la realidad, la construimos de acuerdo a múltiples intereses. Entonces, y de acuerdo a ello, sobre intensificar el análisis sobre la forma expresiva de la cultura política de la época, es perderse en la propia época. Eso se denomina «el riesgo hermenéutico» y uno de los autores citado por Mc Evoy que cayó en eso en pleno siglo xx fue Giddens (1987), cuando fue asesor de Blair, uno de los teóricos referenciales del texto.

¿Cómo salir de esa aporía? Para encontrar una respuesta veamos a nuestros autores clásicos que trabajaron el tema. Ni Haya de la Torre ni Mariátegui confundieron la construcción del Estado por el que apostaban con las vicisitudes del estado que pretendían construir los criollos desde los tiempos independentistas. Por eso es que ellos no confundieron la utopía republicana del siglo XIX, con la utopía real de las mayorías nacionales. ¿Y dónde se encontraba esa distinción? En el contenido estatal de su proyecto el cual definía clara y nítidamente dos tipos de actores: enemigos al cual ese estado debía enfrentar y sus actores de apoyo al cual ese estado debía integrar. Pero, la base de las identidades de los actores que este estado debía enfrentar, por un lado, e integrar por otro, se encuentra en el sistema de constricciones y restricciones, pero también de oportunidades y aperturas, institucionales de ese momento histórico. En el terreno de la historicidad de ese momento en el cual los actores procesaban sus oposiciones, luchas, antagonismos y conflictos pero que ellos mismos los interpretaban con los dispositivos imaginarios de su época, y que por eso terminaban confundiendo sus deseos políticos con la realidad social que los contextuaba. En el caso de Haya de la Torre y Mariátegui esa confusión no se produjo y hacían una clara distinción entre el Estado que querían construir y la vida material en cual los actores ubicaban su arraigo social. En una palabra, distinguían con claridad lo político de lo económico, la propuesta abstracta de universalidad estatal con la particularidad concreta de la economía (o mejor «economías») cotidianas 5 . Por eso, para Haya de la Torre el Estado debía ser antiimperialista ya que esa sujeción institucionalizaba bloqueos de desarrollo, igualmente para Mariátegui,

5 Este tema se analiza en las ciencias sociales como la disociación entre la razón sustantiva histórica política y la razón instrumental económica acumulativa. Es solo en las sociedades bajo acumulación de la forma valor, es decir modernas, que se produce tal disociación, y no así en las sociedades tradicionales. Al respecto véase de Jurgen Habermas Problemas de legitimación en el capitalismo tardio, Ediciones Amorrortu,1975. Si se confunden esos dos racionalidades y no se analiza la disociación se cae en «el riesgo hermenéutico» y en lugar hacer análisis histórico político se termina haciendo descriptivismo histórico político, incluso con estilos sumamente eruditos. 
aunque él no perfiló con tanta nitidez quehaceres estatales y mas bien se abocó a los organizacionales culturales. Nos queda el sabor de señalar que probablemente ese es el análisis que debió hacerse en torno a la figura de Manuel Pardo antes de quedarnos en la verbalización de lo que el mismo propuso y que no era más que la cultura re-imaginada de su época.

No basta decir, entonces, que como se había dado un ciclo de expansión exportadora previa a la guerra con Chile, eso posibilitó el surgimiento de una burguesía civilista que disputaba su hegemonía sobre el caudilismo histórico representado por Ramón Castilla. Eso es caer, nuevamente, en la verbalización de los propios actores. Ciertamente se quebró en parte el sistema institucional cerrado de dominación señorial hacendaria previa al surgimiento del civilismo pardista, pero en ningún momento el civilismo como partido analizó ni diagnóstico el entorno geopolítico de actores externos que buscaban mantener, por intereses de acumulación, a los actores caudillistas tradicionales. Es decir, intensificando su vocación estatista moderna con la normatividad que el supuesto estado civilista debiera tener confundían su actuación en la escena política criolla con las condiciones de la nación en su conjunto como macro sistema integral. Y por, eso porque no confundieron los dos planos y de lo concreto particular con lo abstracto utópico estatal no sólo Haya de la Torre y Mariátegui optaron por otras propuestas de construcción estatal, sino que sus acompañantes intelectuales de la misma generación - Basadre por ejemplo — mirando bajo otros ojos la realidad de ese tiempo e integrando los dos planos de la acción social, señalaron lo inoportuno que es afirmar que había cultura cívica bajo ese período. No fue por omisión como se señala sino por profundización del análisis que generalizaron sus propuestas.

El tema de los avatares histórico políticos republicanos para lograr la ansiada promesa de construir un estado democrático efectivo es sumamente vasto y amplio, y en esa perspectiva los recientes trabajos de diversos autores que han logrado poner sobre el debate, el republicanismo es sumamente interesante, y en esa línea el texto de Mc Evoy, y reflexionando a partir del mismo después de un par de décadas de su primera edición, es un avance importante, en especial porque ofrece una lectura más acorde con tiempos reflexivos hermenéuticos, además que nos presenta una exhaustiva revisión historiográfica sobre un período importante en esa línea de construcción estatal. Un avance sobre el pasado, pero que podría tener cierto sesgo de riesgo epistémico sino se tiene en cuenta, con detenimiento, las figuraciones simbólicas políticas de los propios actores de época y la propia historicidad envolvente - tanto externa como interna- que sobrepasa a sus propios actores. 


\section{Referencias}

Adrianzén, A. (Compilador) (1987). Pensamiento político peruano. 3 volúmenes. Lima: Ediciones DESCO.

Apel, K. (1985). La transformación de la filosofía. I-II volúmenes. Madrid: Ediciones Taurus.

BASAdre, J. (1983). Historia de la República del Perú. 11 volúmenes. Lima: Editorial Universitaria.

Basadre, J. (1931). Perú problema y posibilidad. Ensayo de una sintesis de la evolución histórica del Perú. Lima: Ediciones Rosay.

Bonilla, H. (1980). Un siglo a la deriva: Ensayos sobre Perú, Bolivia y la guerra. Lima: Instituto de Estudios Peruanos.

Bonilla, H. (1974). Guano y burguesía en el Perú. Lima: Instituto de Estudios Peruanos.

Cotler, J. (1978). Clases, Estado y nación en el Perú. Lima: Instituto de Estudios Peruanos.

De Soто, H. (1986). El otro Sendero. Lima: Ediciones El Barranco.

Flores G., A. y M. Burga (1980). Apogeo y crisis de la República Aristocrática. Lima: Ediciones Rickchay Perú.

Flores Galindo, A (1988). República sin ciudadanos. En Buscando un Inca. Lima: Editorial Horizonte.

Gadamer, H. (2010). Verdad y método. Salamanca: Ediciones Sígueme.

Giddens, A. (1997). Política, sociología y teoría social. Reflexione sobre el pensamiento social clásico y contemporáneo. Madrid: Ediciones Paidós.

Habermas, J. (1987). Teoría de la acción comunicativa. I-II volúmenes. Madrid: Ediciones Taurus.

Haya de la Torre, V. (1936). El antiimperialismo y el APRA. Lima: Editorial Fondo del Congreso de la República».

Mariátegui, J. (1987). 7 ensayos de interpretación de la realidad peruana. Lima: Ediciones Amaut, (primera edición 1928).

Mc Evor, C. (s.f.). La utopia republicana. Ideales y realidades en la formación de la cultura política peruana (1871-1919). Lima: Fondo Editorial Pontificia Universidad Católica del Perú.

Mc Evoy, C. (1994). Un proyecto Nacional en el siglo XIX. Lima: Fondo editorial Universidad Pontifica Católica del Perú.

Murra, J. (1975). Formaciones económicas y politicas del mundo andino. Lima: Instituto de Estudios Peruano.

Rostoroswski, M. (1983). Estructuras andinas del poder. Ideología religiosa y politica. Lima: Instituto de Estudios Peruanos.

Vergara, A. (2013). Ciudadanos sin república. De la precariedad institucional al descalabro político. Lima: Ediciones Planeta.

Yépez del Castillo, E. (1972). Perú 1820-1920. Un siglo de desarrollo capitalista en el Perú. Lima: Instituto de Estudios Peruanos. 